\title{
The Effect of a Dietary Carbohydrase Enzyme System on Blood Glucose Levels When Combined with Foods of Varying Glycemic Index in Male Sprague-Dawley Rats
}

\author{
Mark L. Anderson \\ $R \& D$ Department, Triarco Industries, Wayne, New Jersey, USA.
}

\begin{abstract}
Extensive research has shown that physical performance and recovery can be improved by maintaining or enhancing glucose availability. Carbogen ${ }^{\circledR}$ (Triarco Industries, Wayne, NJ, USA), a patented dietary fungal carbohydrase enzyme system, converts complex carbohydrates and fiber into simpler carbohydrates when ingested. Supplementing the enzymatic digestion of complex carbohydrates and fiber that may be digested very slowly or not at all in vivo may increase the availability of glucose. This may be reflected by increased absorption rates and higher measurable levels of whole blood glucose (WBG) that may be bioavailable for extended energy production. These preliminary investigations evaluate the ability of Carbogen to produce a rapid and more sustained increase in WBG levels when combined with a variety of food substrates commonly used by athletes and non-athletes to increase levels of physical activity. To investigate this, food substrates having a low, moderate, or high glycemic index (GI) with various amounts of total carbohydrates and dietary fiber were used. The individually tested substrates include soy nuts, cooked pasta, meal replacement bars, a nutrition shake, and a carbohydrate sports supplement. The investigations presented here consist of seven separate preclinical rat feasibility studies conducted over a period of approximately 12 months. The collective results presented here identify specific attributes of a category of food substrates common to sports nutrition enthusiasts that may significantly increase WBG levels over an extended time when dosed with Carbogen. Specifically, using Carbogen with a food substrate having a low or moderate GI and containing dietary fiber may increase the rate of glucose absorption and maintain significant increases in WBG levels.
\end{abstract}

KEY WORDS: • Carbogen $\bullet$ dietary enzyme $\bullet$ food substrate $\bullet$ fungal carbohydrase $\bullet$ glucose absorption rate $\bullet$ glycemic index

\section{INTRODUCTION}

$\mathbf{R}$ ESEARCH HAS SHOWN that the level of physical activity can be increased by maintaining or enhancing carbohydrate availability, which in turn optimizes muscle and liver carbohydrate stores and maintains blood glucose (BG) levels. ${ }^{1}$ During high intensity $\left(70-85 \%\right.$ of maximal $\mathrm{O}_{2}$ consumption) physical activity and prolonged aerobic exercise nearly all of the energy utilized is derived from carbohydrate-based fuel. ${ }^{1-3}$

As early as 1924 Levine et al. ${ }^{4}$ linked low BG levels with fatigue in athletes. In this study, marathon runners who maintained high levels of BG throughout the race had significantly improved performance. More recent studies have shown that consuming substantial amounts of carbohydrates $(>200 \mathrm{~g}$ ) in the 4-hour period preceding exercise can promote endurance. ${ }^{5}$ It can also enhance an athlete's performance in timed trials following a session of prolonged exercise. ${ }^{6,7}$ This improvement has been linked to sustained high rates of carbohydrate oxidation, maintenance of plasma glucose levels, and conservation of liver glycogen. ${ }^{8,9}$ Fatigue

Manuscript received 24 November 2010. Revision accepted 8 July 2011.

Address correspondence to: Mark L. Anderson, Triarco Industries, 400 Hamburg Turnpike, Wayne, NJ 07470, USA, E-mail: Mark.Anderson@triarco.com has been shown to occur when BG and liver and muscle glycogen decrease past a specific threshold. ${ }^{10}$

The carbohydrate requirement for optimal athletic performance can range from $60 \%$ to $70 \%$ of total energy intake. ${ }^{11}$ Although there are various dietary plans and supplements available to accommodate athletes' increased carbohydrate needs, the type of carbohydrate supplied may affect performance. Simple carbohydrates are classified as having a high $(>70)$ glycemic index (GI) as assigned by the international table of glycemic index and glycemic load values. ${ }^{12}$ These carbohydrates produce a greater rise and fall in postprandial $\mathrm{BG}$ and a greater overall $\mathrm{BG}$ response during the first 2 hours after consumption than foods having a moderate $(56-69)$ or low $(<55)$ GI as classified by the American Diabetes Association. ${ }^{13}$ High GI foods also induce a greater rise in blood insulin in the immediate postabsorptive period, leading to lower concentrations of the body's two main metabolic fuels, BG and fatty acids. ${ }^{12}$ Simple carbohydrates would not be recommended for the endurance athlete because a rapid decline in metabolic fuel levels may lead to rapid fatigue. Foods with a moderate or low GI contain higher levels of complex carbohydrates and fiber. They produce a lower overall postprandial glucose and insulin response during the first 2 hours after consumption. ${ }^{12}$ Based on the results of recent studies some sports 
nutritionists promote foods with a GI of $<55$ for preexercise meals. Thomas et al. ${ }^{14}$ for example, showed that cyclists who consumed low GI foods 1 hour before training had longer times to fatigue than cyclists who consumed an equivalent amount of carbohydrates from high GI foods. ${ }^{14}$

However, there is a limitation where the ability of muscle to absorb glucose from the blood exceeds the rate which the gastrointestinal tract can transport usable carbohydrates into the blood. ${ }^{15}$ In these situations the ingestion of a fungal carbohydrase enzyme system with low to moderate GI food substrates may be helpful to increase glucose liberated from food. It has been reported that adding a fungal carbohydrase to a test meal prior to ingestion can alter the kinetics of $\mathrm{BG} .{ }^{16}$ When ingested, a precisely formulated carbohydrase system may increase the rate of glucose absorption from complex carbohydrates and fiber by supplementing endogenous carbohydrase enzymes and providing cellulase, thereby producing an additional source of glucose by breaking down cellulose. This may increase exogenous glucose absorption kinetics resulting in increased levels of whole BG (WBG) readily available for energy production. The amount of increase, however, may be significantly influenced by the GI and the amounts of complex carbohydrate and fiber in the food substrate. A food substrate with a high GI containing no complex carbohydrates or fiber may show no difference in WBG levels. Food substrates having low or moderate GI may show significant increases in WBG levels over time that may be readily bioavailable for energy production.

The purpose of the present studies is to investigate the ability of Carbogen ${ }^{\circledR}$ (Triarco Industries, Wayne, NJ, USA), a patented fungal carbohydrase enzyme system, to produce a rapid, sustained increase in WBG levels when ingested with various food substrates. They included low GI foods, low and moderate GI meal replacement bars, a moderate GI nutrition shake, and a high GI dietary supplement. Studies presented here were performed in the rat model as preclinical feasibility and substrate screening studies prior to testing the efficacy of Carbogen in humans.

\section{MATERIALS AND METHODS}

\section{Food substrates}

The food substrates were chosen based on relevance to sports nutrition enthusiasts and as examples of low, moderate, and high GI foods as categorized by the American Diabetes Association. ${ }^{13}$ The GI of each food substrate reported here is based on glucose equal to 100 and is considered to be approximate because of reported inherent variations in results and the methodology to determine the value. ${ }^{12}$ Percentage total carbohydrate, dietary fiber, protein and total fat are listed for each food substrate tested. The amount of complex carbohydrate, carbohydrate subtypes, and fiber subtypes for most substrates were unavailable and therefore not reported.

\section{Animals}

All study protocols were approved by and performed at Qualtech Laboratories (Ocean, NJ, USA) under guidelines of the American Association for Laboratory Animal Science using as few animals as possible. Male SpragueDawley rats $(250-300 \mathrm{~g}$ in body weight) were obtained from Hilltop Lab Animals (Scottdale, PA, USA), placed in quarantine for at least 1 week, and maintained on a diet of Purina $^{\circledR}$ (St. Louis, MO, USA) rat chow 5012 (60\% total carbohydrate, $5 \%$ dietary fiber, $20 \%$ protein, and $4 \%$ fat). All animals were fasted for 24 hours before test initiation with water provided ad libitum. All dosing, blood collection, and analyses were performed by qualified laboratory animal technicians. Prior to these studies it was determined that three rats per group was sufficient to detect differences in WBG levels between groups by the glucose tolerance test. Two groups of three rats each were used per food substrate: one group was the test group, and the other group was the control group.

\section{Dosing}

The Carbogen dose ranged from 1 to $3 \mathrm{mg} / \mathrm{g}$ of carbohydrate. The formula was based on the U.S. patent. ${ }^{17}$ The amount used for each study was determined based on the total carbohydrate content of each food substrate and dosed as milligrams of Carbogen per gram of carbohydrate. Total carbohydrate content was taken from the nutrition facts panel and is considered approximate.

\section{Test and control food substrate preparation}

Individual food substrates were prepared in sterile water and divided into two separate containers: the appropriate amount of Carbogen was added to one container just prior to dosing and designated the test container; the other container was designated the control. Both the test and control were administered at a dose of $1 \mathrm{~mL} / 100 \mathrm{~g}$ of body weight per rat directly into the stomach via oral gavage.

Substrate 1 (dried, roasted soy nuts, unsalted [U.S. Soy Distributors, Mattoon, IL, USA]: GI=18, 33\% total carbohydrate, $8 \%$ dietary fiber, $35 \%$ protein, $25 \%$ total fat). The test article was prepared by making a puree of the dried soybeans in sterile water at a ratio of $1 \mathrm{~g}$ of dried soybean: $2.5 \mathrm{~mL}$ of water. The puree contained approximately $0.13 \mathrm{~g}$ of carbohydrate $/ \mathrm{mL}$. Carbogen (lot number CAG-XJ01) was mixed into the puree at a concentration of $1 \mathrm{mg} / \mathrm{g}$ of carbohydrate just prior to dosing.

Substrate 2 (Pastina pasta-1 [Ronzoni ${ }^{\circledR}$, New World Pasta, Harrisburg, PA, USA]: GI=41, 75\% total carbohydrate, $21 \%$ dietary fiber, $12 \%$ protein, $2 \%$ total fat). The test article was prepared by making a puree of cooked pasta in sterile water. The puree contained approximately $0.28 \mathrm{~g}$ of carbohydrate/mL. Carbogen (lot number CAG-XJ01) was mixed into the puree at a concentration of $1 \mathrm{mg} / \mathrm{g}$ of carbohydrate just prior to dosing.

Substrate 3 (Pastina pasta-1.5 [Ronzoni]: GI=41, 75\% total carbohydrate, $21 \%$ dietary fiber, $12 \%$ protein, $2 \%$ 
total fat). The test article was prepared as above, and the same lot of Carbogen was mixed into the puree at a concentration of $1.5 \mathrm{mg} / \mathrm{g}$ of carbohydrate just prior to dosing.

Substrate 4 (fudge brownie Met-Rx ${ }^{\circledR}$ [NBTY, Bohemia, $N Y$, USA] meal replacement bar: GI $=58,65 \%$ total carbohydrate, $3 \%$ dietary fiber, $34 \%$ protein, $7 \%$ total fat). The test article was prepared by grinding and dissolving the meal replacement bar in sterile water at a ratio of $1 \mathrm{~g}: 2.5 \mathrm{~mL}$. The solution contained approximately $0.26 \mathrm{~g}$ of carbohydrate/mL. Carbogen (lot number CAG-XJ01) was mixed into the solution at a concentration of $1 \mathrm{mg} / \mathrm{g}$ of carbohydrate just prior to dosing.

Substrate 5 (chocolate PR Ironman Bar ${ }^{\circledR}$ meal replacement bar $\left[\right.$ Twinlab $^{\circledR}$, New York, NY, USA]: GI $=39,40 \%$ total carbohydrate, $0 \%$ dietary fiber, $30 \%$ protein, $30 \%$ total fat). The test article was prepared by grinding and dissolving the meal replacement bar in sterile water at a ratio of $1 \mathrm{~g}: 2.5 \mathrm{~mL}$ of water. The solution contained approximately $0.16 \mathrm{~g}$ of carbohydrate $/ \mathrm{mL}$. Carbogen (lot number CAG-XJ01) was mixed into the solution at a concentration of $1 \mathrm{mg} / \mathrm{g}$ of carbohydrate just prior to dosing.

Substrate 6 (Myoplex ${ }^{\circledR}$ vanilla nutrition shake [EAS ${ }^{\circledR}$, Columbus, OH, USA]: GI=62, 28\% total carbohydrate, $4 \%$ dietary fiber, $54 \%$ protein, $6 \%$ total fat). The test article was prepared by dissolving the powdered nutrition shake in sterile water to a concentration of $0.372 \mathrm{~g} / \mathrm{mL}$. The solution of dissolved nutrition shake contained approximately $0.165 \mathrm{~g}$ of carbohydrate $/ \mathrm{mL}$. Carbogen (lot number CAG-XJ01) was mixed into the solution at a concentration of $1 \mathrm{mg} / \mathrm{g}$ of carbohydrate just prior to dosing.

Substrate 7 (CarbPro ${ }^{\circledR}$ maltodextrin powdered supplement $\left[\right.$ Prolab $^{\circledR}$ Nutrition, East Rutherford, NJ, USA]: $G I=95,95 \%$ total carbohydrate, 0\% dietary fiber, $0 \%$ protein, $0 \%$ total fat). The test article was prepared by dissolving the powdered supplement in sterile water to a concentration of $1 \mathrm{~g} / \mathrm{mL}$. The solution contained approximately $0.95 \mathrm{~g}$ of carbohydrate $/ \mathrm{mL}$. Carbogen (lot number CAG-XJ01) was mixed into the solution at a concentration of $3 \mathrm{mg} / \mathrm{g}$ of carbohydrate just prior to dosing.

\section{Blood sampling}

Whole blood samples $(0.5 \mathrm{~mL})$ were collected by tail artery puncture at baseline and at regular intervals following dosing ( $t=0,0.5,1.0,1.5,2.0,3.0,4.0$, and 5.0 hours). Anesthesia with ketamine/thorazine was used as needed. The samples were analyzed immediately after being drawn for glucose levels using a calibrated Encore glucometer (Bayer Diagnostics, Tarrytown, NY, USA). WBG levels were read and reported as milligrams per deciliter. The glucometer was calibrated after each use to ensure accuracy.

\section{Statistical analysis}

The WBG levels from each study were averaged following baseline (hour 0) subtraction and recorded as mean \pm SEM values. The WBG levels for each study were measured and evaluated for significant differences for treatment hours 1-4 using Student's $t$ test at a significance level of .05 and for statistical power. Results of all studies were further evaluated to determine significant differences in treatment and time as well as interactions between groups by two-way analysis of variance (ANOVA) at a significance level of .05. Bonferroni's multiple comparisons test was also implemented at a significance level of .05 to determine any significant treatment effects at individual time points. Statistical analyses were performed using SPSS Graduate Pack version 11.0 software (SPSS Inc., Chicago, IL, USA).

\section{RESULTS}

Each food substrate represents a separate study. Results from all seven studies are summarized in Table 1. All statistical analyses were performed following baseline (hour 0) subtraction.

\section{Substrate 1 (soy nuts [U.S. Soy])}

Oral dosing of a puree of soy nuts (approximate GI $=18$ ) containing $0.13 \mathrm{mg}$ of Carbogen and approximately $0.13 \mathrm{~g}$ of carbohydrate $/ \mathrm{mL}$ resulted in a $24 \mathrm{mg} / \mathrm{dL}$ increase of average WBG levels compared with controls (Fig. 1). This increase was significant $(P=.05)$ for hours $1-4$ using the one-tailed Student's $t$ test and reported a statistical power of 1.0. Analysis by two-way ANOVA reported significant $(P=.05)$ treatment and time effects but no significant interaction between the test and control groups (Fig. 1). Bonferroni's multiple comparisons test indicated significant $(P=.05)$ treatment effects between test group for hours $0.5-$ 2 and control group for hour 4 as well as test group for hours 0.5-2 and control group for hour 5.

\section{Substrate 2 (pasta-1, pastina [Ronzoni])}

A puree of cooked pastina pasta (approximate $\mathrm{GI}=41$ ) containing $0.28 \mathrm{mg}$ of Carbogen and approximately $0.28 \mathrm{~g}$ of carbohydrate $/ \mathrm{mL}$ resulted in a $15 \mathrm{mg} / \mathrm{dL}$ increase of average WBG levels compared with controls. This increase did not reach statistical significance $(P=.05)$ for hours $1-4$ using the one-tailed Student's $t$ test and reported a statistical power of 0.19 . No significant differences were reported using two-way ANOVA or Bonferroni's multiple comparisons test $(P=.05)$.

\section{Substrate 3 (pasta-1.5, pastina [Ronzoni])}

A second puree of cooked pasta (approximate $\mathrm{GI}=41$ ) containing $0.420 \mathrm{mg}$ of Carbogen and approximately $0.28 \mathrm{~g}$ of carbohydrate $/ \mathrm{mL}$ resulted in a $7 \mathrm{mg} / \mathrm{dL}$ increase of average WBG levels compared with controls. This increase was significant $(P=.05)$ for hours $1-4$ using the one-tailed Student's $t$ test and reported a statistical power of 0.62. No significant differences were reported using two-way ANOVA or Bonferroni's multiple comparisons test $(P=.05)$. 
Table 1. Summary of Preclinical Trials with Carbogen in Male Rats

\begin{tabular}{|c|c|c|c|c|c|c|}
\hline Food substrate & $\begin{array}{l}\text { Glycemic } \\
\text { index }\end{array}$ & $\begin{array}{l}\text { Total } C \\
\text { and } F \\
(\%)\end{array}$ & $\begin{array}{l}\text { Carbogen dose } \\
\text { in test group } \\
\quad(\mathrm{mg} / \mathrm{mL})\end{array}$ & $\begin{array}{c}\text { Approximate carbohydrate } \\
\text { dose in test and control } \\
\text { group }(\mathrm{g} / \mathrm{mL})\end{array}$ & $\begin{array}{c}\text { Average baseline subtracted } \\
\text { whole blood glucose levels } \\
\text { in group for hours } 1-4 \\
{[\text { mean }( \pm S E M)](\mathrm{mg} / \mathrm{dL})}\end{array}$ & $\begin{array}{l}\text { Statistical } \\
\text { power }\end{array}$ \\
\hline Substrate 1 (soy nuts) & 18 & $\begin{array}{l}\text { C } 33 \% \\
\text { F } 8 \%\end{array}$ & 0.13 & 0.13 & $\begin{array}{l}\text { Test } 60( \pm 8.7) \\
\text { Control } 36( \pm 7.5)\end{array}$ & $1.0^{* \dagger}$ \\
\hline Substrate 2 (Pastina pasta-1) & 41 & $\begin{array}{l}\text { C } 75 \% \\
\text { F } 21 \%\end{array}$ & 0.28 & 0.28 & $\begin{array}{l}\text { Test } 57( \pm 10.1) \\
\text { Control } 42( \pm 4.3)\end{array}$ & 0.19 \\
\hline Substrate 3 (Pastina pasta-1.5) & 41 & $\begin{array}{l}\text { C } 75 \% \\
\text { F } 21 \%\end{array}$ & 0.42 & 0.28 & $\begin{array}{l}\text { Test } 32( \pm 6.1) \\
\text { Control } 25( \pm 8.1)\end{array}$ & $0.62^{*}$ \\
\hline Substrate 4 (Met-Rx MRB) & 58 & $\begin{array}{l}\text { C } 65 \% \\
\text { F } 3 \%\end{array}$ & 0.26 & 0.26 & $\begin{array}{l}\text { Test } 88( \pm 11.7) \\
\text { Control } 24( \pm 4.6)\end{array}$ & $0.93^{* \dagger \dagger}$ \\
\hline Substrate 5 PR Ironman Bar & 39 & $\begin{array}{l}\text { C } 40 \% \\
\text { F } 0 \%\end{array}$ & 0.16 & 0.16 & $\begin{array}{l}\text { Test } 34( \pm 18.1) \\
\text { Control } 25( \pm 15.5)\end{array}$ & 0.35 \\
\hline Substrate 6 (Myoplex shake) & 62 & $\begin{array}{l}\text { C } 28 \% \\
\text { F } 4 \%\end{array}$ & 0.165 & 0.165 & $\begin{array}{l}\text { Test } 24( \pm 6.7) \\
\text { Control } 14( \pm 3.2)\end{array}$ & 0.19 \\
\hline Substrate 7 (CarbPro) & 95 & $\begin{array}{l}\text { C } 95 \% \\
\text { F } 0 \%\end{array}$ & 3 & 1 & $\begin{array}{l}\text { Test } 133( \pm 5.2) \\
\text { Control } 115( \pm 25.3)\end{array}$ & 0.22 \\
\hline
\end{tabular}

*Significant $(P=.05)$ difference by Student's $t$ test in average whole blood glucose levels between test and control group for hours $1-4$.

'Indicates significant $(P=.05)$ treatment and time effect with no significant interaction between groups by two-way analysis of variance.

${ }^{\dagger \dagger}$ Indicates significant $(P=.05)$ treatment and time effect as well as significant interaction between groups by two-way analysis of variance.

$\mathrm{C}$, carbohydrate; F, dietary fiber; MRB, meal replacement bar.

\section{Substrate 4 (fudge brownie Met-Rx meal replacement bar)}

A solution of dissolved fudge brownie Met-Rx meal replacement bar (approximate $\mathrm{GI}=58$ ) containing $0.26 \mathrm{mg}$ of Carbogen and approximately $0.26 \mathrm{~g}$ of carbohydrate $/ \mathrm{mL}$ ( $1 \mathrm{mg}$ of Carbogen/g of carbohydrate) resulted in a $64 \mathrm{mg} /$ $\mathrm{dL}$ increase of average WBG levels compared with controls. This increase was significant $(P=.05)$ for hours $1-4$ using the one-tailed Student's $t$ test and reported a statistical power of 0.93. Further analysis using two-way ANOVA reported significant $(P=.05)$ treatment and time effects with

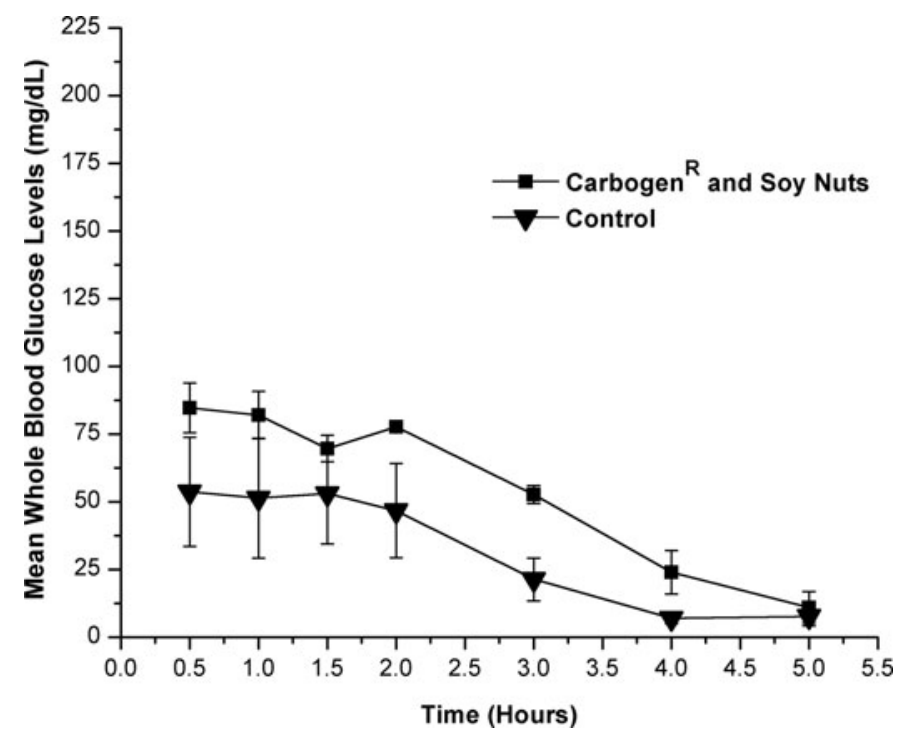

FIG. 1. Effect of Carbogen ( $1 \mathrm{mg} / \mathrm{g}$ of substrate) and soy nuts as a food substrate versus soy nuts control on blood glucose levels (in mg/ $\mathrm{dL}$ ) in male rats. All time points plotted following baseline (hour 0) subtraction. significant interaction between the test and control group. No significant differences were reported using Bonferroni's multiple comparisons test $(P=.05)$. However, the results suggest an increased rate of glucose absorption and a sustained increase in WBG levels over controls (Fig. 2).

\section{Substrate 5 (PR Ironman Bar, chocolate)}

A solution of dissolved Chocolate PR Ironman Bar (approximate $\mathrm{GI}=39$ ) containing $0.16 \mathrm{mg}$ of Carbogen and approximately $0.16 \mathrm{~g}$ of carbohydrate $/ \mathrm{mL}$ ( $1 \mathrm{mg}$ of Carbogen/g

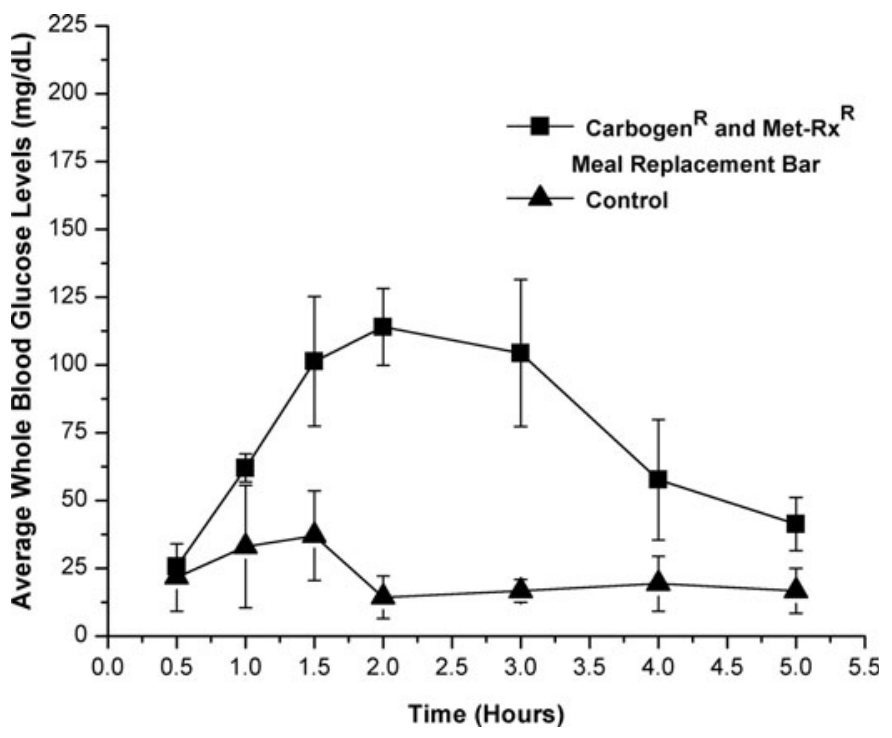

FIG. 2. Effect of Carbogen (1 mg/g of substrate) and Met-Rx meal replacement bar as a food substrate versus Met-Rx meal replacement bar control on blood glucose levels (in $\mathrm{mg} / \mathrm{dL}$ ) in male rats. All time points plotted following baseline (hour 0) subtraction. 


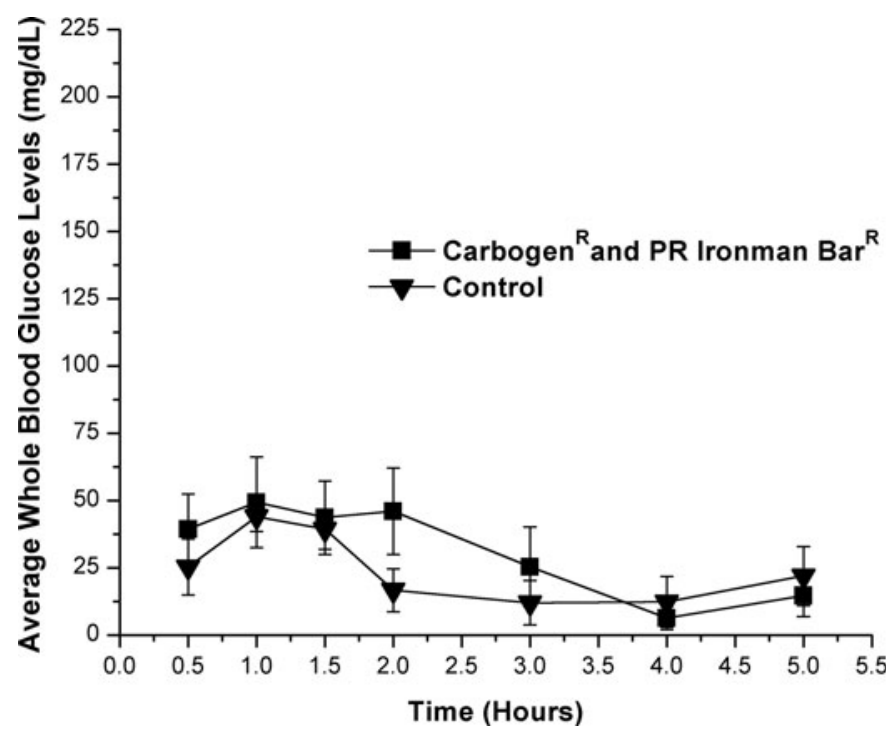

FIG. 3. Effect of Carbogen ( $1 \mathrm{mg} / \mathrm{g}$ of substrate) and PR Ironman Bar as a food substrate versus PR Ironman Bar control on blood glucose levels (in $\mathrm{mg} / \mathrm{dL}$ ) in male rats. All time points plotted following baseline (hour 0) subtraction.

of carbohydrate) resulted a $9 \mathrm{mg} / \mathrm{dL}$ increase of in average WBG levels compared with controls (Fig. 3). This increase did not reach statistical significance $(P=.05)$ for hours $1-4$ using the one-tailed Student's $t$ test and reported a statistical power of 0.35 . No significant $(P=.05)$ differences were reported using two-way ANOVA or Bonferroni's multiple comparisons test.

\section{Substrate 6 (Myoplex nutrition shake, vanilla)}

A solution of dissolved nutrition shake (approximate $\mathrm{GI}=62$ ) containing $0.165 \mathrm{mg}$ of Carbogen and approximately $0.165 \mathrm{~g}$ of carbohydrate $/ \mathrm{mL}$ ( $1 \mathrm{mg}$ of Carbogen $/ \mathrm{g}$ carbohydrate) resulted in a $10 \mathrm{mg} / \mathrm{dL}$ increase of average WBG levels compared with controls. This increase did not reach statistical significance $(P=.05)$ for hours $1-4$ using the onetailed Student's $t$ test and reported a statistical power of 0.19. No significant $(P=.05)$ differences were reported using twoway ANOVA or Bonferroni's multiple comparisons test.

\section{Substrate 7 (CarbPro maltodextrin powdered supplement)}

A solution of the dissolved maltodextrin supplement (approximate $\mathrm{GI}=95$ ) containing $3 \mathrm{mg}$ of Carbogen and approximately $1 \mathrm{~g}$ of carbohydrate $/ \mathrm{mL}$ ( $3 \mathrm{mg}$ of Carbogen $/ \mathrm{g}$ of carbohydrate) resulted in an $18 \mathrm{mg} / \mathrm{dL}$ increase of average WBG levels compared with controls (Fig. 4). This increase did not reach statistical significance $(P=.05)$ for hours $1-4$ using the one-tailed Student's t test and reported a statistical power was 0.22 . No significant $(P=.05)$ differences were reported using two-way ANOVA or Bonferroni's multiple comparisons test.

\section{DISCUSSION}

The results of these studies show that Carbogen, a dietary fungal carbohydrase enzyme system, can significantly

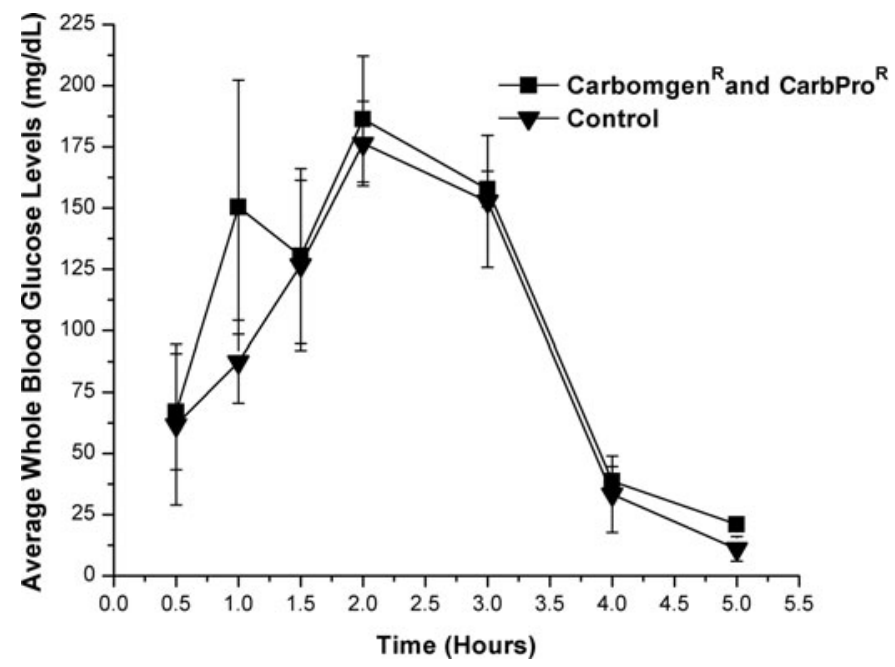

FIG. 4. Effect of Carbogen ( $1 \mathrm{mg} / \mathrm{g}$ of substrate) and CarbPro maltodextrin dietary supplement as a food substrate versus CarbPro control on blood glucose levels (in $\mathrm{mg} / \mathrm{dL}$ ) in male rats. All time points plotted following baseline (hour 0) subtraction.

$(P<.05)$ increase average WBG levels with an appropriate food substrate in the male Sprague-Dawley rat. The results in Table 1 show significant differences in average WBG levels between the test and control groups for hours 1-4 following baseline (hour 0) subtraction using the one-tailed Student's $t$ test and the statistical power for each study. These preliminary statistical analyses were done because of the small dose groups used. Analyses were performed at predicted peak WBG levels to screen for significant differences $(P<.05$, statistical power $>0.6)$ between test and control groups with food substrates having a low $(<55)$, moderate $(56-69)$, and high (>70) GI. Significant differences in average WBG levels between test group and controls are reported in the soy nut $(\mathrm{GI}=18)$, pasta-1.5 $(\mathrm{GI}=41)$, and the Met-Rx meal replacement bar $(\mathrm{GI}=58)$ studies. The statistical power for each of these studies is greater than 0.6. These food substrates have a low to moderate GI and contain some amount of dietary fiber. The Ironman Bar $(\mathrm{GI}=39)$ and CarbPro $(\mathrm{GI}=95)$ substrates contain no dietary fiber, and average WBG levels of the test groups are not significantly $(P<.05)$ increased over control values. The statistical power for each of these studies is $<0.4$. These results indicate that Carbogen may significantly $(P<.05)$ increase average WBG levels when dosed with food substrates of low $(<55)$ to moderate $(56-69)$ GI containing some dietary fiber. The substrates in the Myoplex shake $(\mathrm{GI}=62)$ study and the pasta-1 $(\mathrm{GI}=41)$ study have a low to moderate GI and contain dietary fiber. Both test groups show increases in average WBG levels over controls. The average WBG levels, however, were not significantly $(P<.05)$ different, and the statistical power in each study is $<0.2$. Increasing the dose of Carbogen in the pasta-1.5 study, from 1 to $1.5 \mathrm{mg} / \mathrm{g}$ of carbohydrate, resulted in a statistically significant $(P<.05)$ increase in test group average WBG levels over controls and a statistical power of $>0.6$. In contrast, a Carbogen dose of $3 \mathrm{mg} / \mathrm{g}$ of carbohydrate in the CarbPro study did not produce a statistically significant 
increase in average WBG levels over controls and a statistical power of 0.2. This suggests that increasing the dose of Carbogen with food substrates of low to moderate GI and containing some dietary fiber may result in significant increases in average WBG levels but not with food substrates of high GI containing no dietary fiber. Together, these results suggest that producing significantly higher levels of WBG with Carbogen may be related to a combination of Carbogen dose, food substrate GI, and dietary fiber content. They also help to demonstrate the purpose and function of a dietary fungal carbohydrase enzyme system designed to increase and maintain WBG levels when combined with food substrates containing complex carbohydrates and dietary fiber. In these studies a specific relationship between WBG levels and substrate total carbohydrate content was not apparent (Table 1). Also, a specific relationship between WBG levels and substrate levels of complex carbohydrates could not be determined because they were not indicated on any of the substrate labels.

Further statistical analysis using two-way ANOVA at a significance level of .05 and Bonferroni's multiple comparisons test at a significance level of .05 resulted in significant differences in only two of the studies: the soy nut study and the Met-Rx meal replacement bar study. Significant $(P=.05)$ treatment and time effects with no significant interaction between the test and control groups using two-way ANOVA was reported when Carbogen was dosed with soy nuts (Fig. 1). Bonferroni's test reported significant treatment effects for hours 0.5-2 relative to hours 4-5 (Fig. 1). These results indicate both test and control groups had significant changes in WBG levels during the study. However, both groups had very elevated baseline average WBG levels of 154-198 mg/dL, which were uncharacteristic of all the other studies, which had average baseline values of 89 $129 \mathrm{mg} / \mathrm{dL}$. This indicates that even though the Student's $t$ test (Table 1) and Bonferroni's test results indicate a true treatment effect at individual time points, the results of the two-way ANOVA and high baseline WBG levels indicate the results may not be a consequence of Carbogen treatment. They may be caused by the rats not being in the fasted state and the WBG levels decreasing over the course of the study.

Significant $(P=.05)$ treatment and time effects as well as significant interaction between the test and control groups were reported using two-way ANOVA when Carbogen was dosed with a Met-Rx meal replacement bar. No significant $(P<.05)$ treatment effects at individual time points were reported using Bonferroni's test; however, the results suggest an increased rate of glucose absorption and sustained increase in WBG levels over controls (Fig. 2). This food substrate appears to have been the best substrate tested to combine with Carbogen for a rapid increase in WBG levels and sustaining that increase over an extended period of time. These results indicate that one determining factor for this type of response with Carbogen is the presence of dietary fiber in the food substrate, and another is a low to moderate GI. When food substrates of low and high GI containing no dietary fiber were dosed with Carbogen, reported average WBG levels were not statistically significant $(P=.05)$ compared with controls using any of the statistical analyses presented here. These substrates included the PR Ironman Bar meal replacement bar and the CarbPro maltodextrin dietary supplement (Figs. 3 and 4).

Further preclinical studies may be warranted to confirm the Carbogen dose and minimum amount of complex carbohydrates and fiber necessary to produce the desired effects. Further studies may also be warranted to investigate the influence of Carbogen on the absorption kinetics of glucose, insulin levels, and glucose disposal.

Clinical investigations may also be warranted to determine if endurance athletes may benefit by adding Carbogen to low and moderate GI foods containing complex carbohydrates and fiber. The results presented here suggest Carbogen may make it possible to improve the performance of endurance athletes. It may increase the rate of glucose absorption, sustaining higher WBG levels, lengthening time to fatigue, and contributing to recovery. Higher WBG levels have been shown to enhance glucose uptake and oxidation during exercise, ${ }^{18,19}$ improving performance and lengthening time to fatigue. ${ }^{4}$ Sustaining WBG levels also has the potential to decrease fatigue during exercise and assist with muscle recovery following exercise. Generally, athletes are instructed to consume approximately $1 \mathrm{~g}$ of carbohydrate $/ \mathrm{kg}$ of body weight within 60 minutes following strenuous exercise to efficiently replace their glycogen stores. However, with more BG available before, during, and after exercise as a result of Carbogen, the recovery process could begin even before additional carbohydrates are consumed. This could perhaps qualify Carbogen as a "precovery" product in the sports nutrition arena.

In conclusion, the results of these preliminary preclinical studies show that Carbogen, a patented dietary fungal carbohydrase enzyme system, can significantly increase WBG levels in the rat model. They also suggest that when given with a specific food substrate having a low or moderate GI and containing dietary fiber, Carbogen may increase the rate of glucose absorption and maintain significant increases in WBG levels. These preclinical results indicate that further studies may be warranted to investigate the influence of Carbogen on a larger variety of food substrates, the absorption kinetics of glucose, insulin levels, and glucose disposal. Clinical investigations may also include the use of Carbogen as a dietary supplement. It may be an important addition to the pretraining and precompetition nutrition of endurance athletes by rapidly increasing and sustaining WBG levels when consumed with low to moderate GI food substrates containing complex carbohydrates and fiber. This combination has potential to decrease fatigue during exercise and assist with muscle recovery following exercise. This could qualify Carbogen as a "precovery" product in the sports nutrition arena.

\section{ACKNOWLEDGMENTS}

M.L.A. thanks QualTech Laboratories, Ocean, NJ, USA for participating as the contract laboratory for this research on behalf of Triarco Industries. M.L.A. also thanks MK 
Laboratories for providing writing services and data analysis on behalf of Triarco Industries.

\section{AUTHOR DISCLOSURE STATEMENT}

M.L.A. is employed as Director of Research and Development by Triarco Industries, which manufactures and markets Carbogen. M.L.A. outlined the protocol and supplied the Carbogen for this study.

\section{REFERENCES}

1. Burke L, Hawley JA: Carbohydrate and exercise. Curr Opin Nutr Metab Car 1999;2:515-520.

2. Romijn J, Coyle EF, Sidossis LA, Gastaldelli A, Horowitz JA, Endert E, Wolfe RR: Regulation of endogenous fat and carbohydrate metabolism in relation to exercise intensity and duration. Am J Physiol 1993;265:E380-E391.

3. Gollnick P: Selective glycogen depletion in human muscle fibers after exercise of varying intensity and at varying pedalling rates. J Physiol 1974;241:45-57.

4. Levine S, Gordon B, Derick CL: Some changes in chemical constituents of blood following a marathon race. JAMA 1924;82: 1778-1779.

5. Wright D, Sherman WM, Dernbach AR: Carbohydrate feedings before, during, or in combination improve cycling endurance performance. J Appl Physiol 1991;71:1082-1088.

6. Neufer P, Costill DL, Flynn MG, Kirwan JP, Mitchell JB, Jernbach A: Improvements in exercise performance: effects of carbohydrate feedings and diet. J Appl Physiol 1987;62:983-988.

7. Sherman W, Brodowicz G, Wright DA, Allen WK, Simonsen J, Dernbach A: Effects of $4 \mathrm{~h}$ preexercise carbohydrate feedings on cycling performance. Med Sci Sports Exerc 1989;21:598-604.
8. Coyle E, Coggan AR, Hemmert MK, Ivy JL: Muscle glycogen utilization during prolonged strenuous exercise when fed carbohydrate. J Appl Physiol 1986;61:165-172.

9. Bosch A, Dennis SC, Noakes TD: Influence of carbohydrate loading on fuel substrate turnover and oxidation during prolonged exercise. J Appl Physiol 1993;74:1921-1927.

10. Sherman W: Metabolism of sugars and physical performance. Am J Clin Nutr 1995;62:228S-241S.

11. Devlin J, Williams C: Final consensus statement: foods, nutrition and sports performance. J Sports Sci 1991;9:iii.

12. Foster-Powell K, Holt SH, Brand-Miller JC: International table of glycemic index and glycemic load values: 2002. Am J Clin Nutr 2002;76:5-56.

13. American Diabetes Association. The Glycemic Index of Foods. www.diabetes.org/food-and-fitness/food/planning-meals/the -glycemic-index-of-foods.html (accessed November 2010).

14. Thomas D, Brotherhood JR, Brand JC: Carbohydrate feeding before exercise: effect of glycemic index. Int J Sports Med 1991;12:180-186.

15. Burke E: Optimal Muscle Performance and Recovery, 2nd ed. Penguin Putnam Inc., New York, 2003.

16. Brudnak M: Enzyme therapy-Part I. Townsend Lett Doctors Patients 2000;209:88-92.

17. Rhode RR Jr, Handel RA, inventors; Triarco Industries, assignee: Carbohydrase enzyme food supplement composition. U.S. patent 5,817,350. October 6, 1998.

18. Ahlborg G, Felig P: Influence of glucose ingestion on fuelhormone response during prolonged exercise. J Appl Physiol 1976;41:683-688.

19. McConell G, McCoy M, Proietto J, Hargreaves M: Skeletal muscle GLUT-4 and glucose uptake kinetics during exercise. $J$ Appl Physiol 1994;77:1565-1568. 